ص ص[7-00]

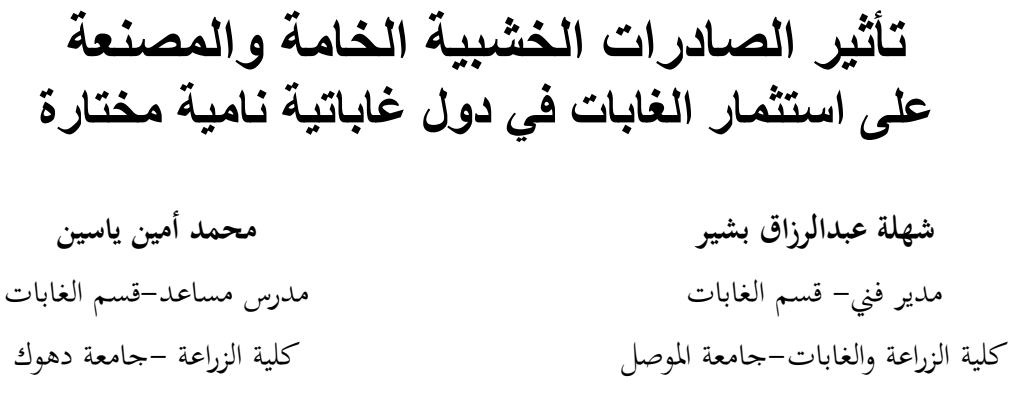

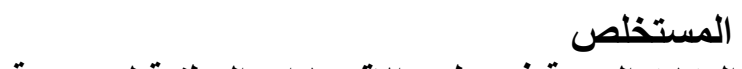

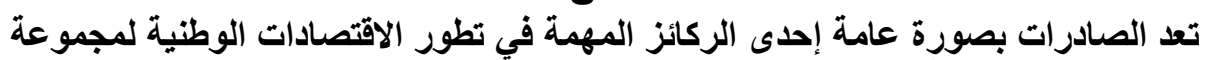

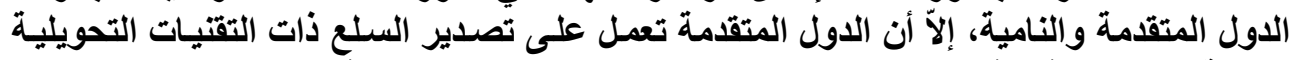

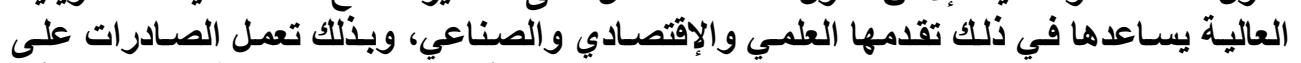

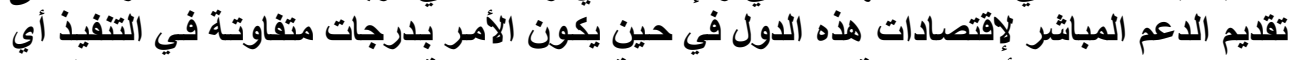

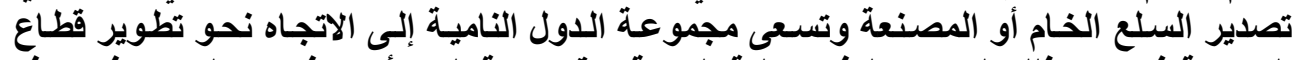

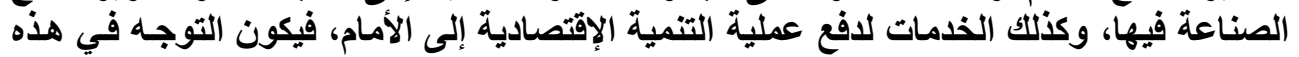

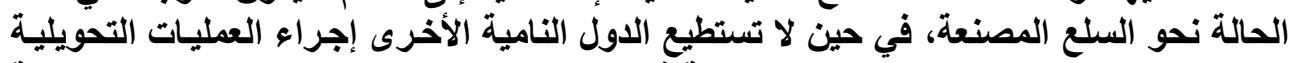

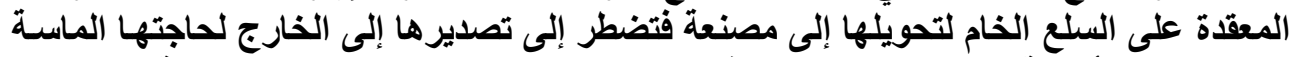

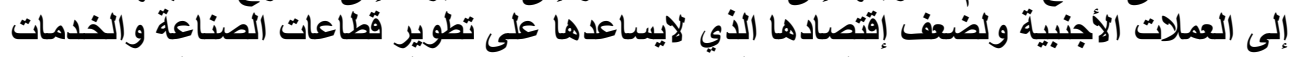

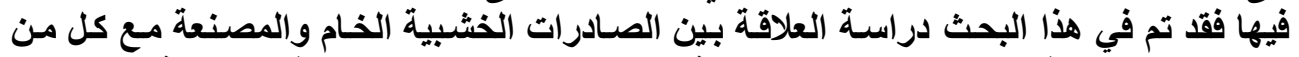

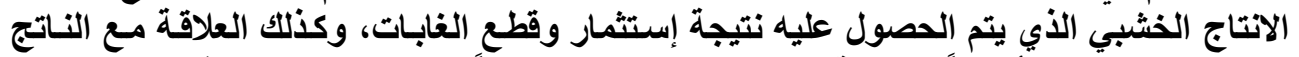

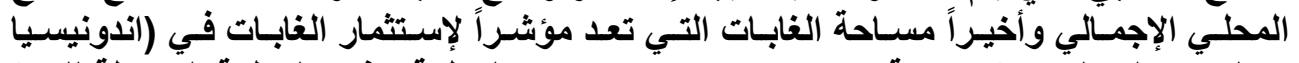

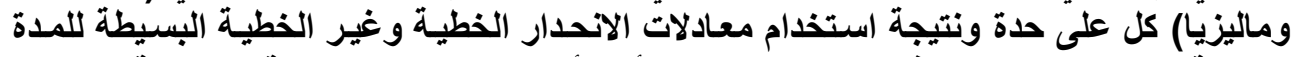

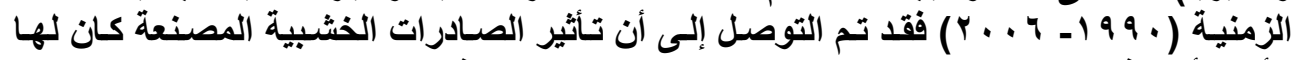

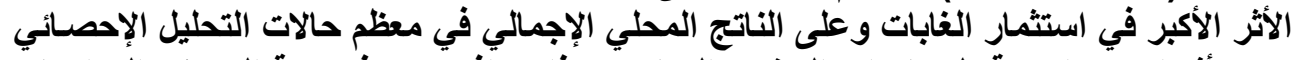

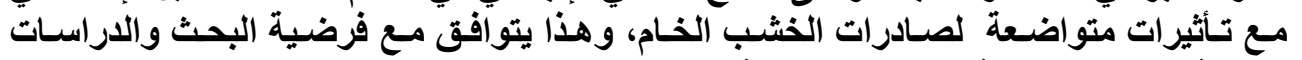

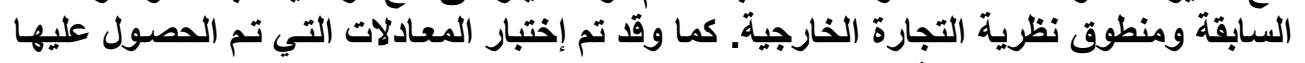
احصائيا وتم تحليل النتائج اقتصادياديا. الكلمات المفتاحية: الصادرات الخثبية، الصادرات الخيات الخثبية الخامة والمصنعة، إستثمار الغابات. 


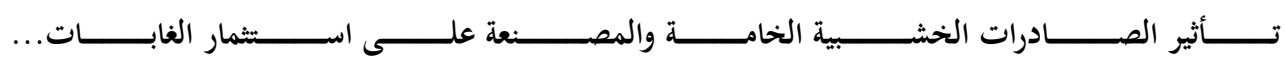

\title{
Influences of Export Raw and Industrial Wood on Forest Utilization in Selected Countries (Indonesia, Malaysia)
}

\author{
Shahla Abd-Al-Razak \\ Department of Forestry \\ University of Mosul
}

\author{
Mohammed A. Yassen \\ Department of Forestry \\ University of Dohuk
}

\begin{abstract}
Exports in general is one of the important pillars in the evolution of national economies of the group advanced and developing countries, but developed countries seek to export goods with high-assisted techniques applied by the scientific, economic, industrial exports, and thus to provide direct support to the economies of these countries. The degree will be varied in implementing the export of any raw or manufactured goods and a group of developing countries. The trend is towards the development of industry and services as well as to advance the economic development that to go forward in this case, some manufactured goods, while other developing countries can boldest complex manufacturing processes for goods raw conversion into manufactured exports, which forced out the urgent need for foreign currencies and the weak economy, which not serve on the development of industry and services sectors and the result of the application of quantitative mathematical models to determine the relationship and effects of exports of raw timber and processed in a sample of countries (Indonesia and Malaysia) show that the effects were different for exports of raw timber and processed timber and the area remains forest production and forest area represented a changing economy, the gross domestic product in Indonesia, the results were more pronounced than in Malaysia has emerged through the use of statistical models of linear regression coefficients that are consistent with the hypothesis of the results of research and studies in place and the other for the former do not agree, particularly in Malaysia which requires attention is the implementation of the Forests and the production Permanent continuing to support the forest sector and make it the best form of his or her duties.

Key words: Export Raw Wood, Export Industrial wood, Forest Products, Development Country

المقدمة

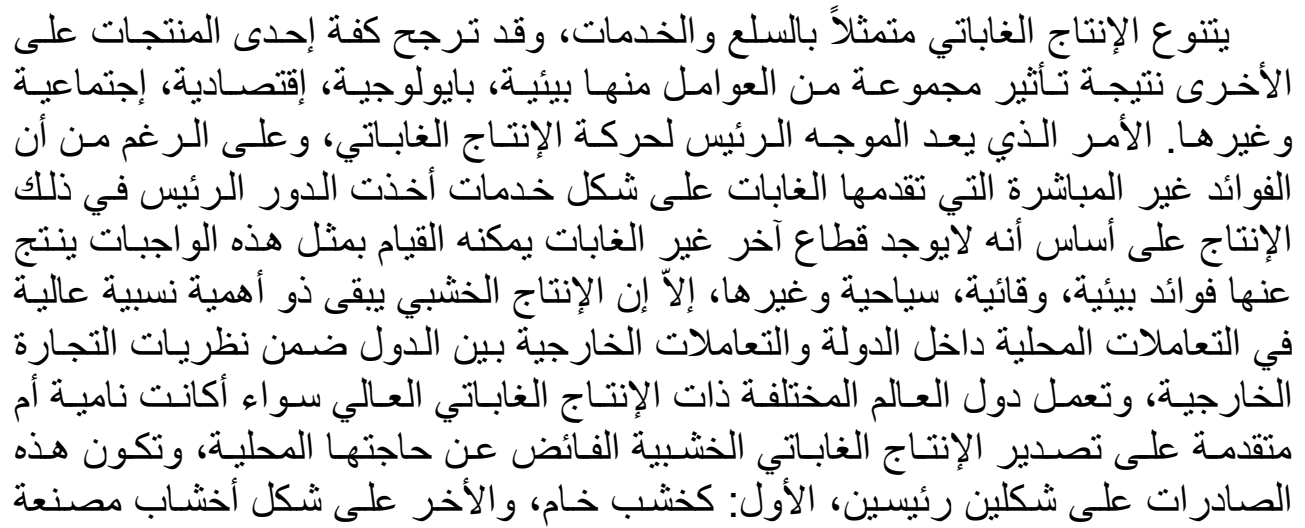


بـV] بشير وياسين

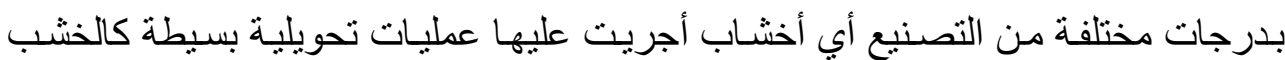

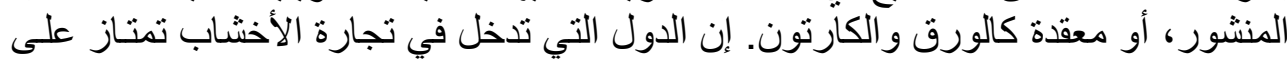

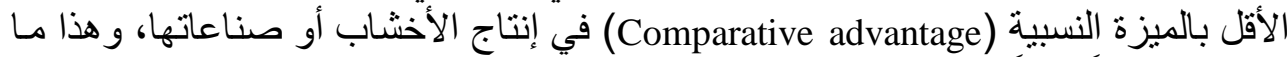

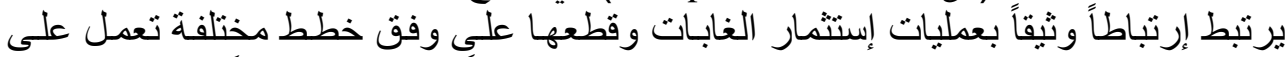

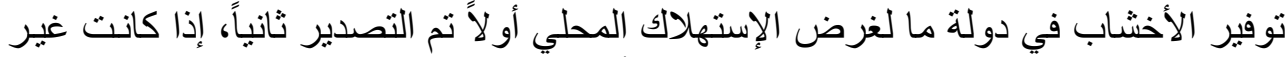

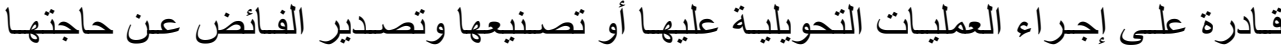

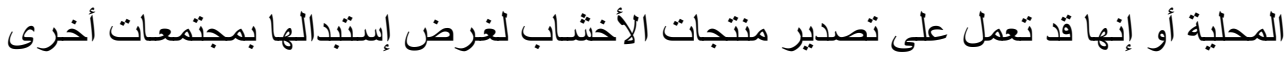
ذات أهمية نسبية أعلى لمجتمعاتها.

مشكلة البحث

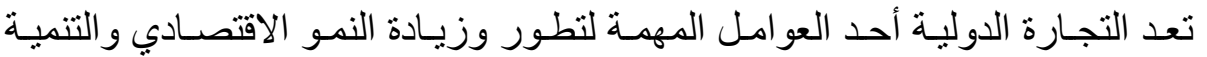

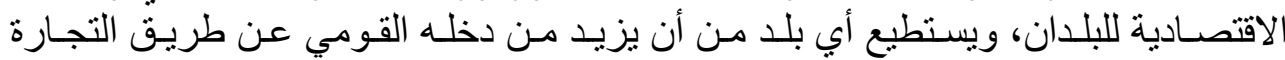

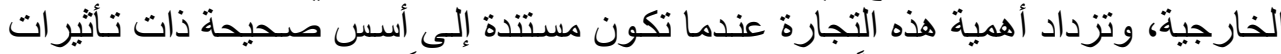

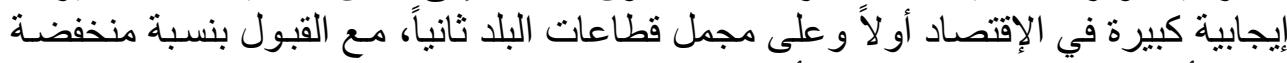

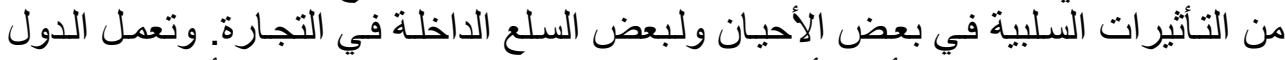

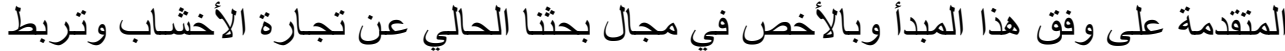

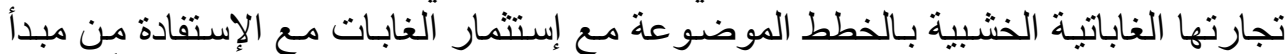

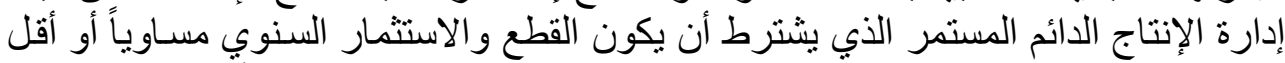

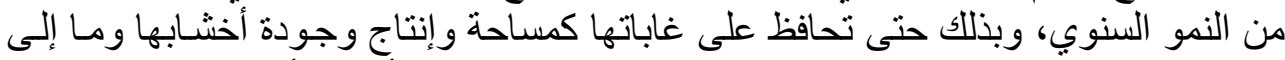
ذلك، ولكن المشكلة تحدث في حالة الدول النامية التي يمكن أن تلجـأ إلى قطع و إستثنمار

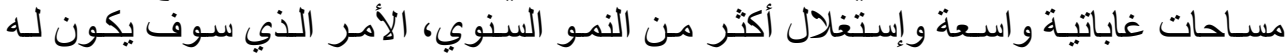

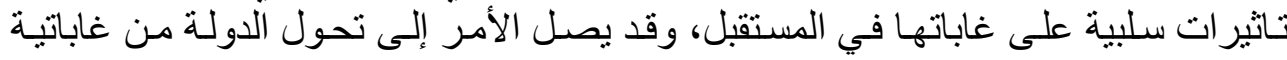

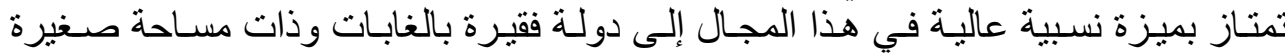

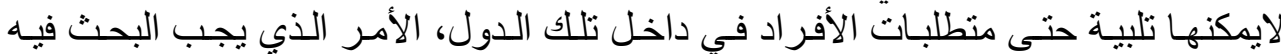

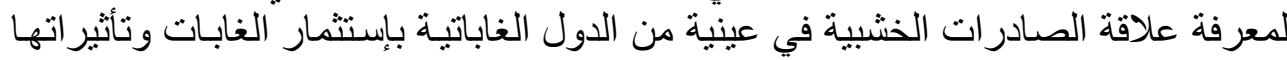

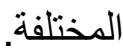

\section{فرضية البحث}

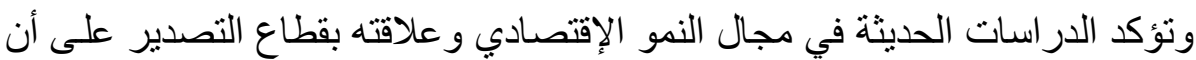

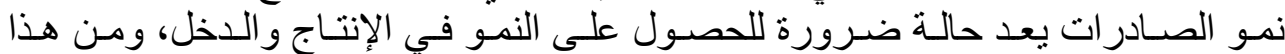

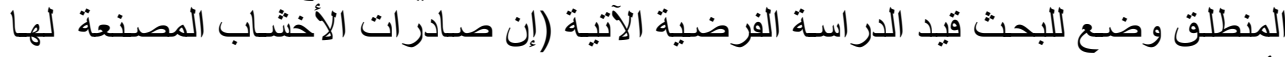

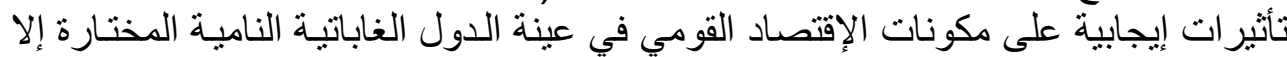

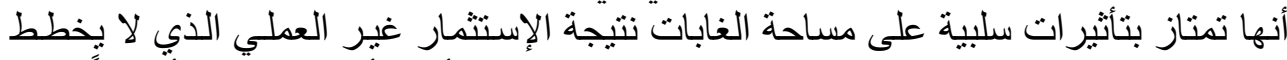

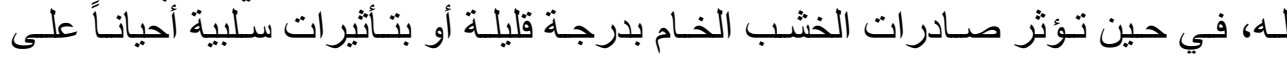

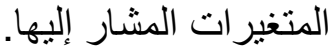

$$
\text { أهداف البحث البحث إلى تحقيق الأهداف الآتية: }
$$




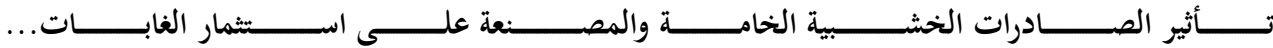

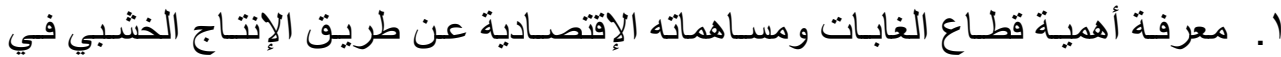

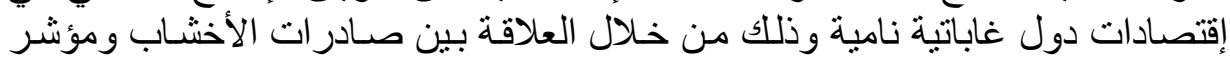
الناتج المحلي الإجمالي (GDP).

r. ت تفسير العلاقة بين التغييرات الحاصلة في مساحة الغابات مع تطور الصـادرات الخشبية

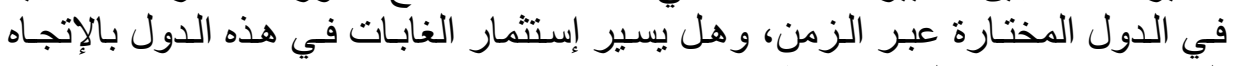

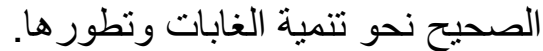

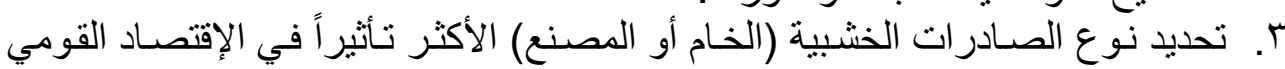

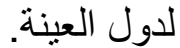

الإطار النظري والدراسات السابقة

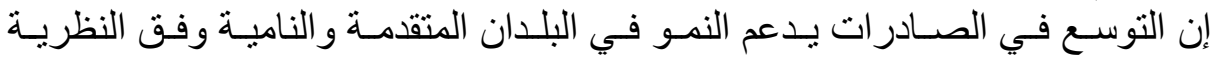

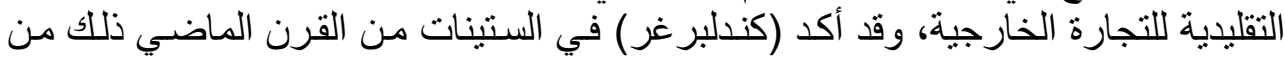

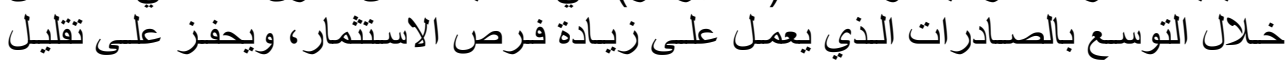

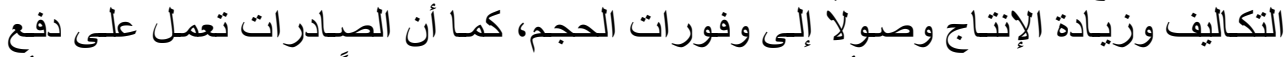

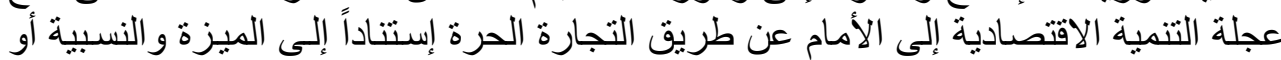

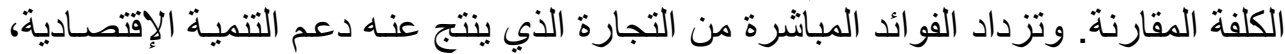

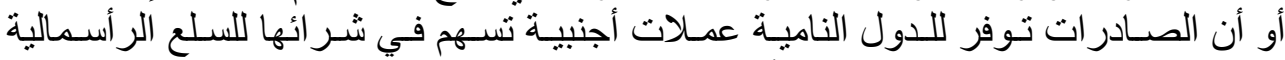

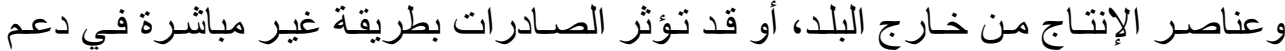

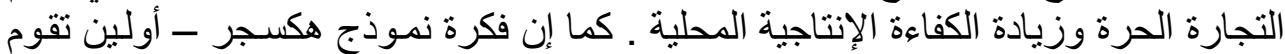

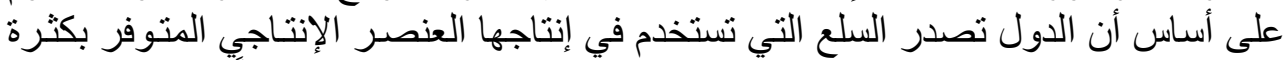

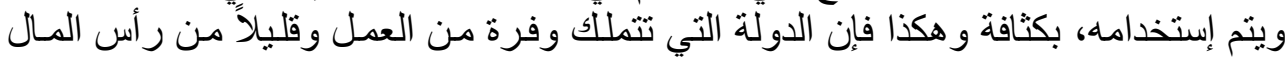
تقوم بتصدير سلع كثيفة العمل، ويعد هذا الأنموذج معالجة لنو اقص نظريـة المبزة النسبية

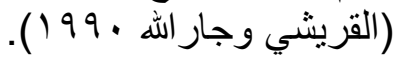

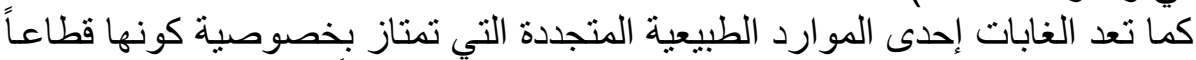

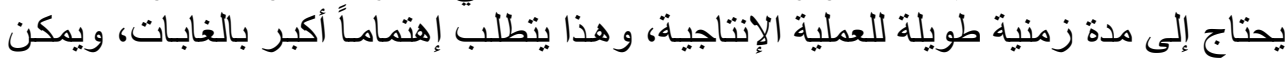

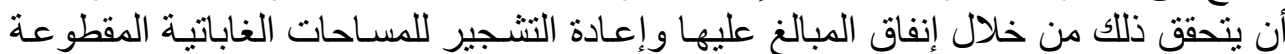

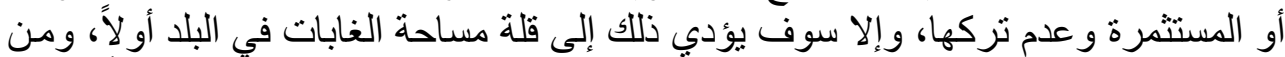

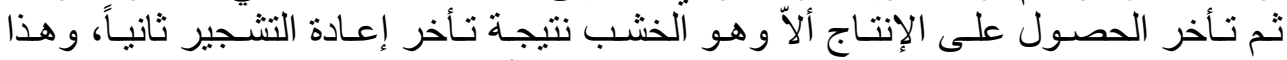

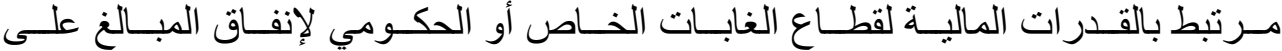

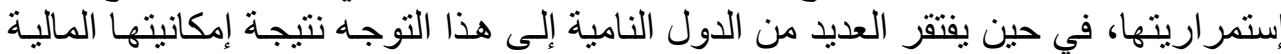

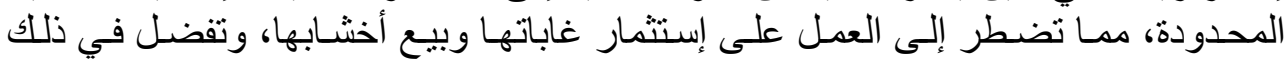

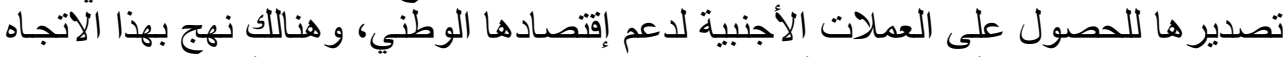

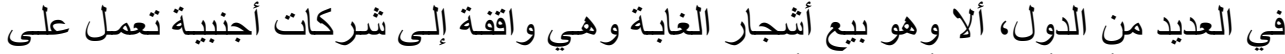

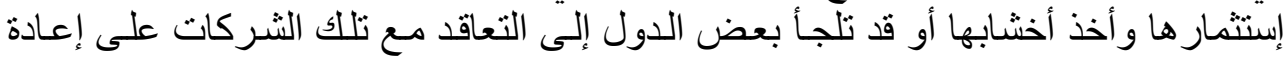

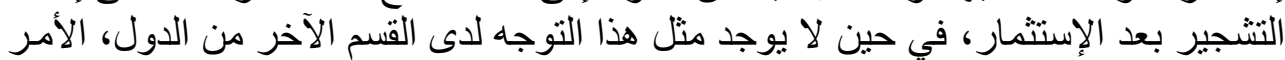

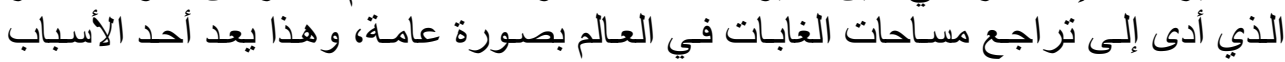
الرئيسة لهذا التراجع. ت التراجع 
بشير وياسين[09]

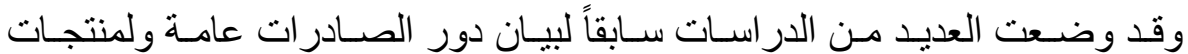

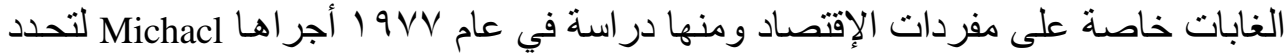

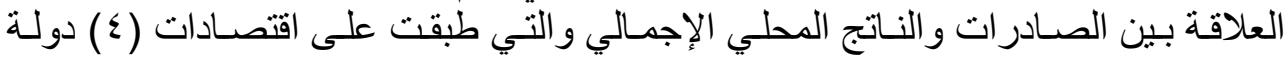

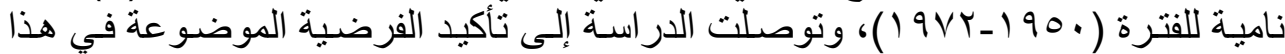

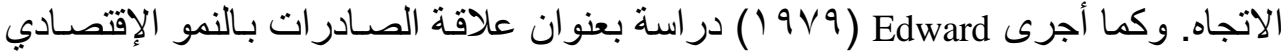

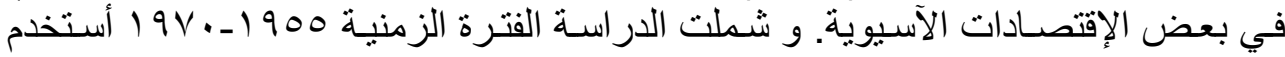

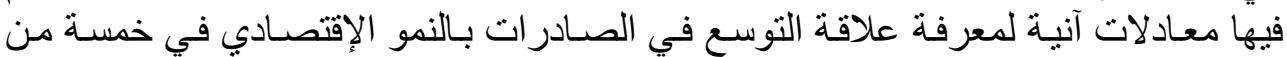

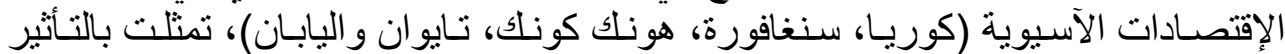

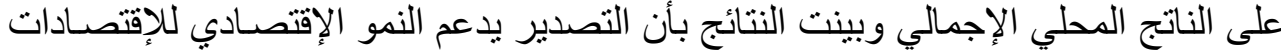

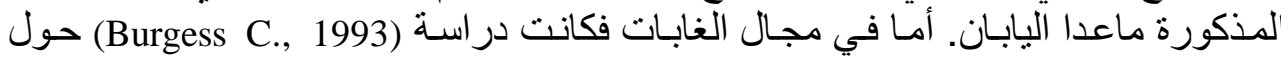

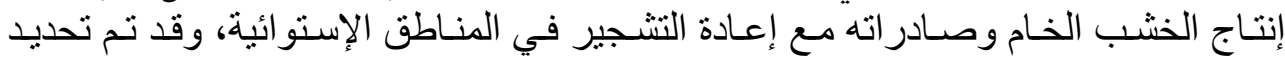

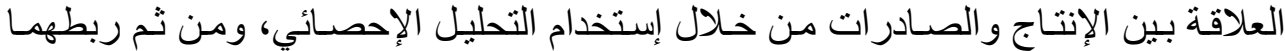

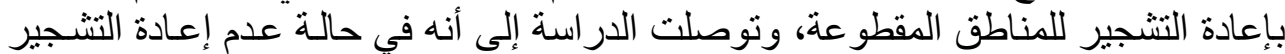

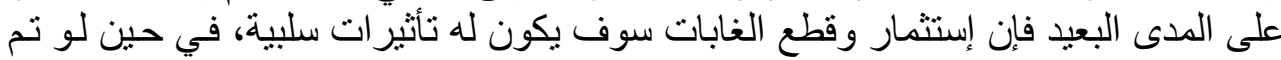

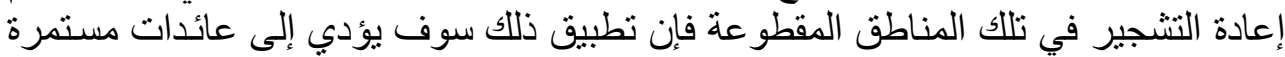

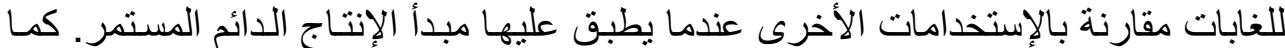

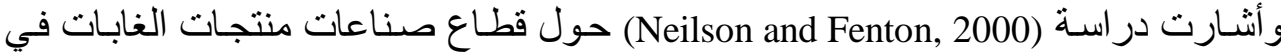

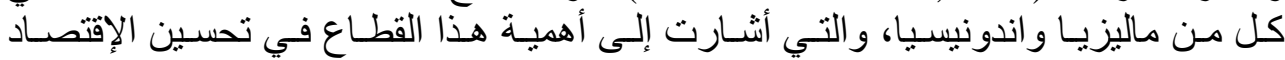

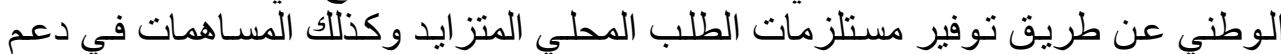
الإقتصاد عن طريق تصدير هذه المنتجات الخشبية المصنعة. بينمـا تشير در اسـة Schuler) et. al,. 2001).

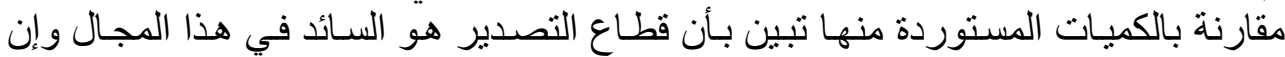
كميات التصدير في تز ايد مستمر وذات التيات نأثير ات إقتصادية إيجابية.

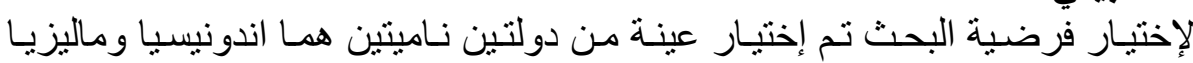

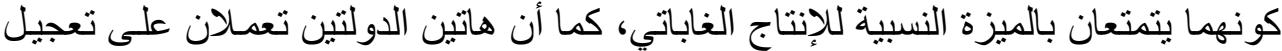

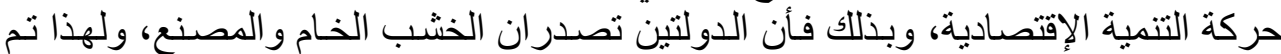

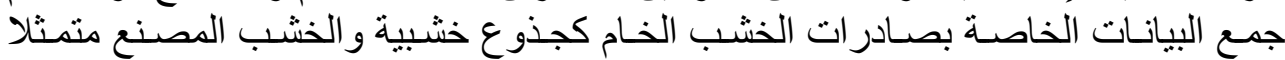

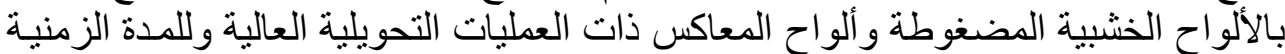

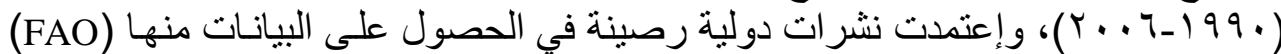

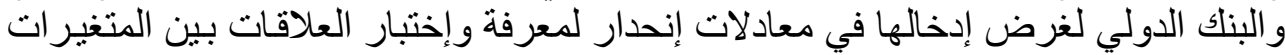

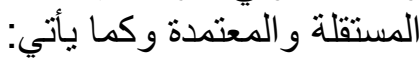
ا ـعلاقة الصادرات الخثبيةً بالإنتاج الغاباتي:

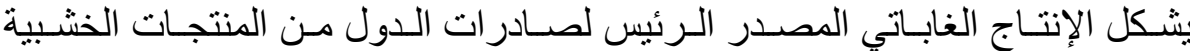

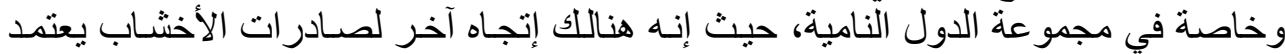

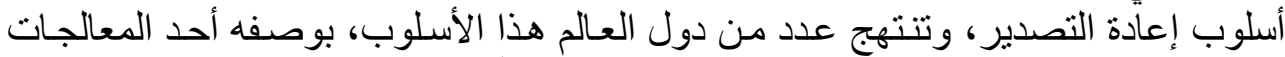

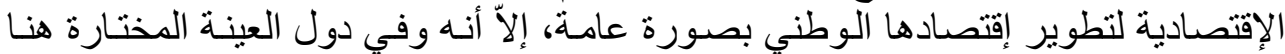

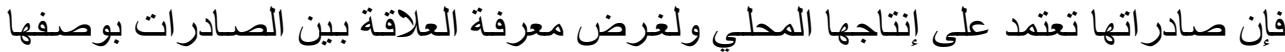




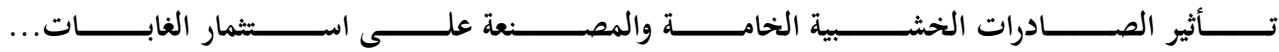

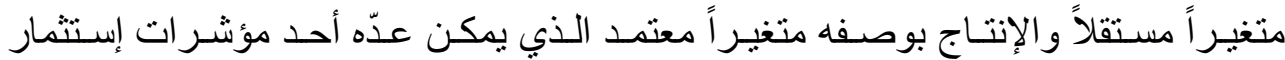

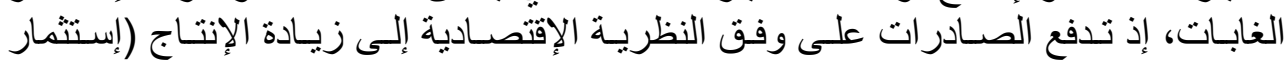

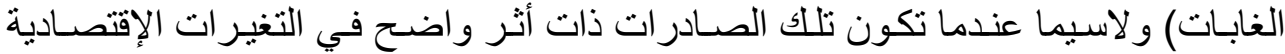

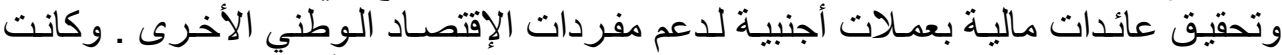

$\mathrm{Y}=\mathrm{a}+\mathrm{b}_{1} \mathrm{X}_{1}$

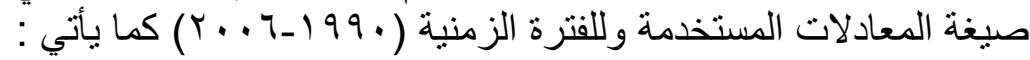

$\mathrm{Y}=\mathrm{a}+\mathrm{b}_{2} \mathrm{X}_{2}$

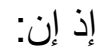

: الإنتاج الغاباتي من الخشب الخام (يمثل إستثمار الغابات أو مقدار القطع السنوي) :Y

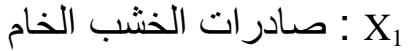

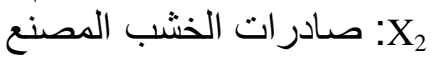

وقد تم تطبيق البيانات التي تم جمعها لدولتي العينة لمعرفة العلاقة وتأثير الصـادرات

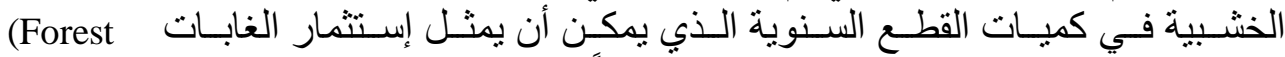
(harvesting)

\section{r r تأثير الصادرات الخشبية في الناتج المحلي الإجمالي}

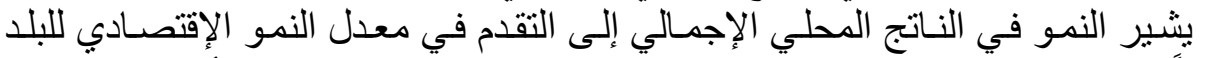

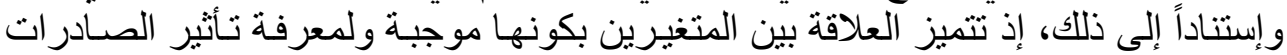

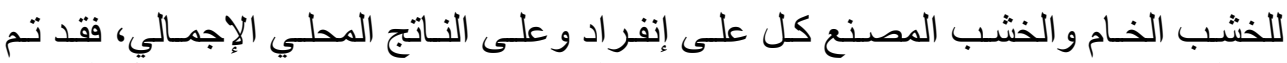

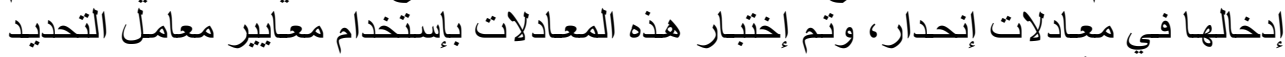

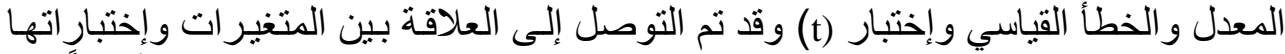

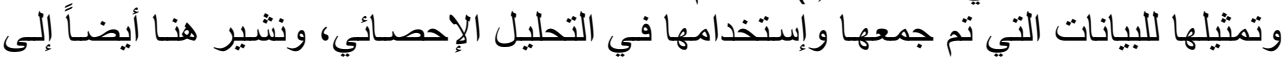

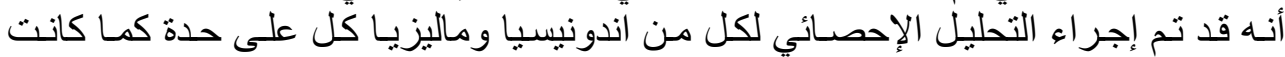

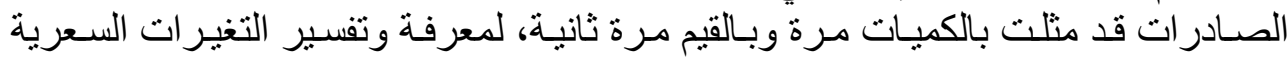

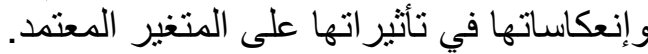

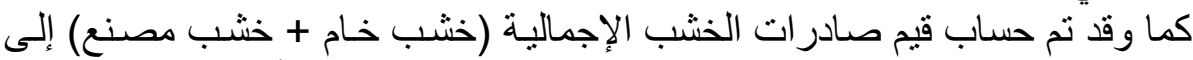

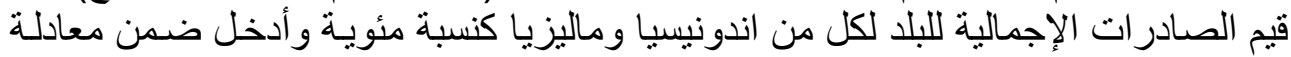

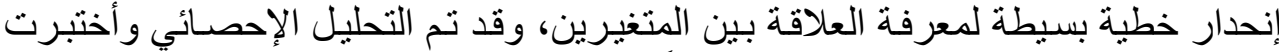
المعادلة باستخدام المعايير المشار إليها سابقاً.

$\mathrm{Y}=\mathrm{a}+\mathrm{bX} \mathrm{X}_{1}$ وكانت المعادلات المستخدمة على النحو الآتي:

$\mathrm{Y}=\mathrm{a}+\mathrm{bX} \mathrm{X}_{2}$

$\mathrm{Y}=\mathrm{a}+\mathrm{bX} \mathrm{X}_{3}$

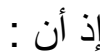

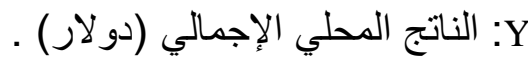

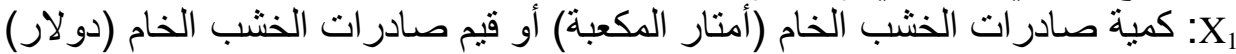
XX (دو لار): X3 
بشير وياسين[1]

r. علاقة صادر ات الأخشاب مع إستثمار الغابات (ممثلا بالمساحة الغاباتية).

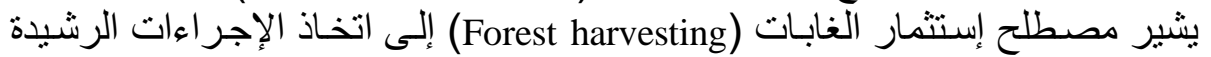

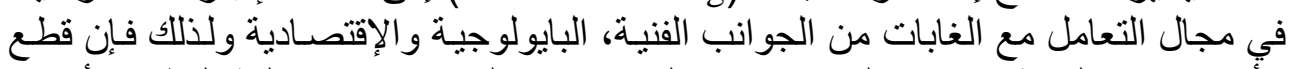

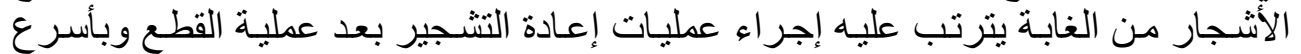

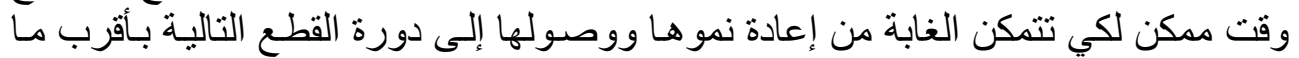

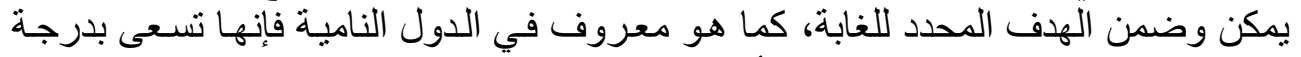

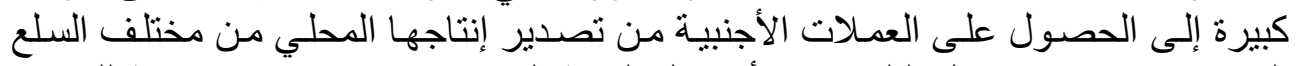

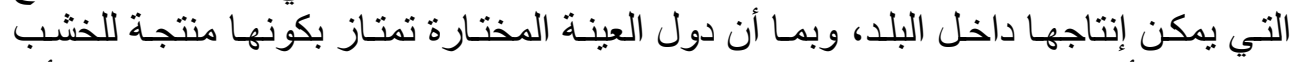

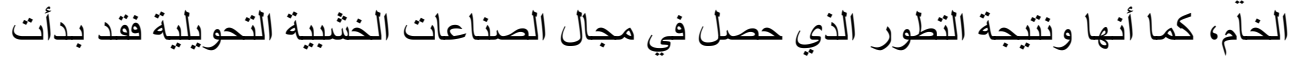

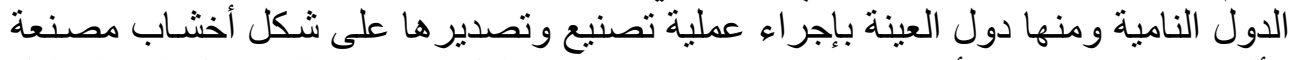

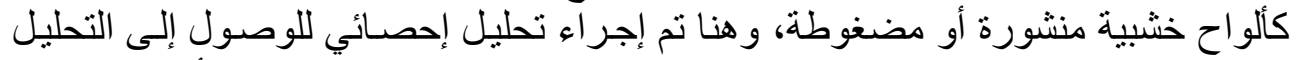

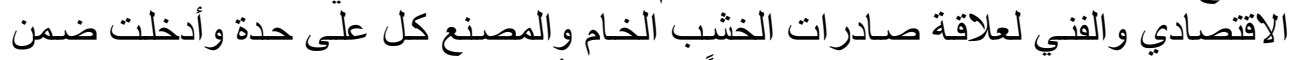

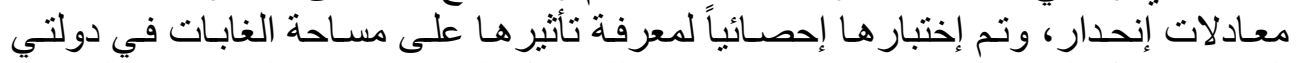

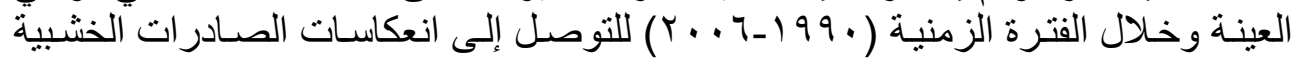

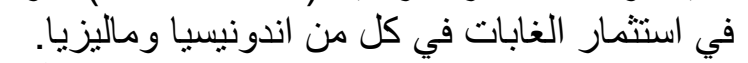

$\mathrm{Y}=\mathrm{a}+\mathrm{bX} \mathrm{X}_{1}$ وكانت المعادلات المستخدمة على الند النحو الآتي :

$\mathrm{Y}=\mathrm{a}+\mathrm{bX} \mathrm{X}_{2}$

حيث إن:

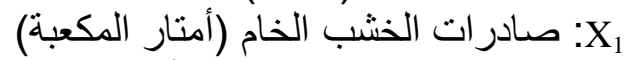

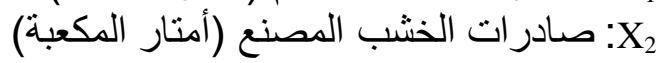

النتائج والمناقشة

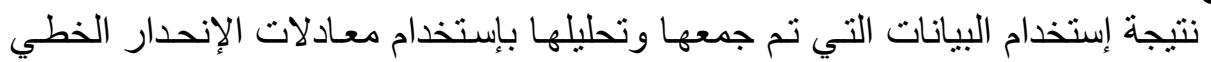

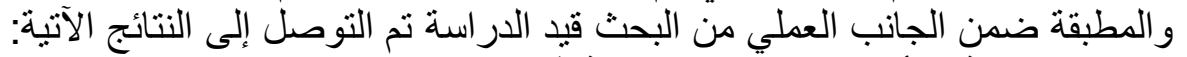

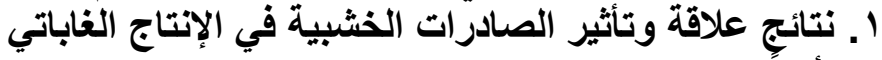

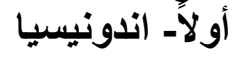

\begin{tabular}{|c|l|c|c|}
\hline $\begin{array}{c}\text { No. of } \\
\text { Equation }\end{array}$ & \multicolumn{1}{|c|}{ Equation } & $\mathbf{R}^{2}$ Adjusted\% & Standard Error \\
\hline 1 & $\begin{array}{l}\mathrm{Y}=1.36689 \mathrm{E} 8-17.443 * \mathrm{X}_{1} \\
\mathrm{~T}(25.5255),(-1.80576)\end{array}$ & 12.3 & 2.0 \\
\hline 2 & $\begin{array}{l}\mathrm{Y}=6.93867 \mathrm{E} 7+8.96617 * \mathrm{X}_{2} \\
\mathrm{~T}(9.35945), \mathrm{T}(8.9136)\end{array}$ & 83.0 & 8.8 \\
\hline
\end{tabular}

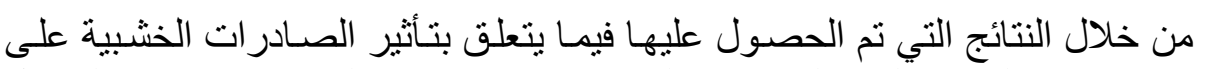

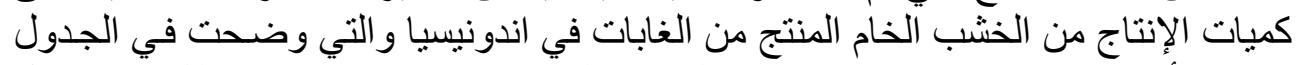

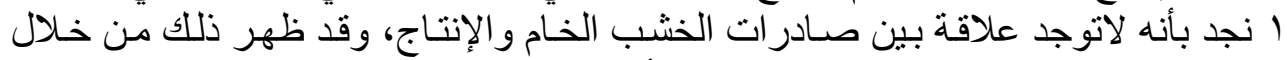

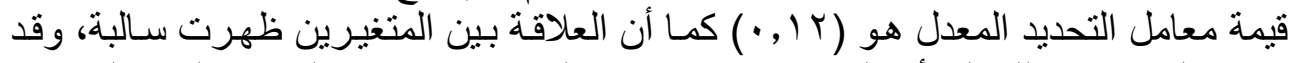

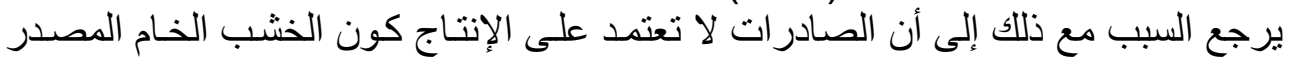




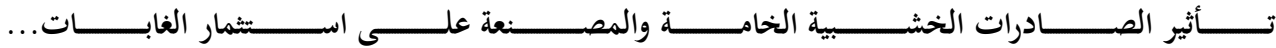

لايعد محفزاً على زيادة الإنتاج نتيجة إنخفاض أسعار الخشب الخام مقارنة بالخشب المصنع

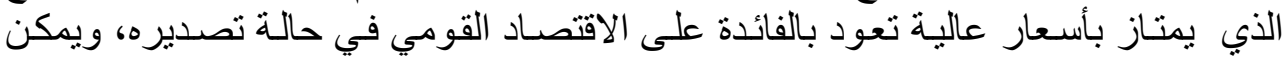

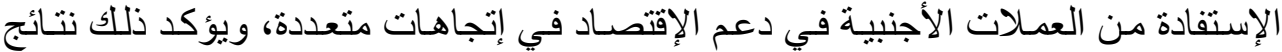

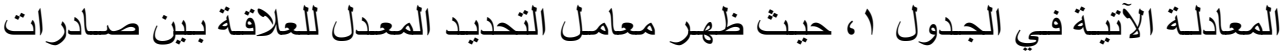

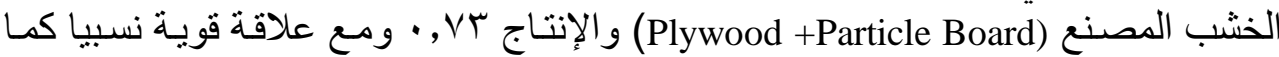

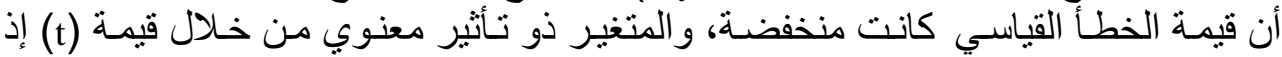

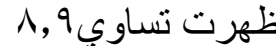

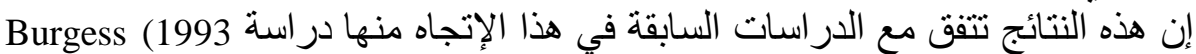

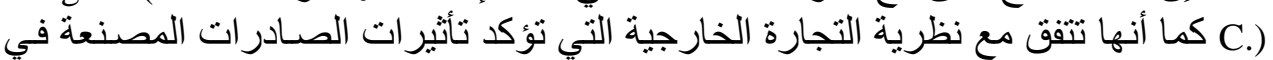

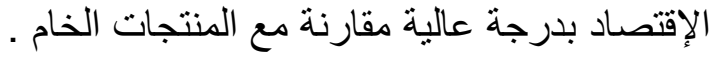

ثانياً- ماليزيا

\begin{tabular}{|c|c|c|c|}
\hline \multicolumn{4}{|c|}{ نتائج علاقة وتأثير الصادرات الخدول الخثبية في الإنتاج الغاباتي } \\
\hline $\begin{array}{c}\text { No. of } \\
\text { Equation }\end{array}$ & Equation & $\mathbf{R}^{2}$ Adjusted \% & Standard Error \\
\hline 1 & $\begin{array}{c}\mathrm{Y}=2.6848 \mathrm{E} 7+0.487197 * \mathrm{X}_{1} \\
\mathrm{~T}(5.02889),(0.899031)\end{array}$ & 0.0 & 1.0 \\
\hline 2 & $\begin{array}{c}\mathrm{Y}=4.96715 \mathrm{E} 7-5.10499 * \mathrm{X}_{2} \\
\mathrm{~T}(15.0226),(-6.20658)\end{array}$ & 70.1 & 5.7 \\
\hline
\end{tabular}

تشير المعادلات التفاضلية في الجدول ب إلى أن الحالة في ماليزيـا ظهر بشكل مغاير

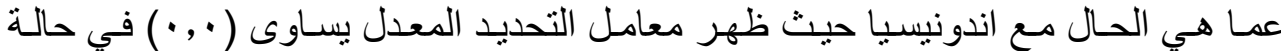

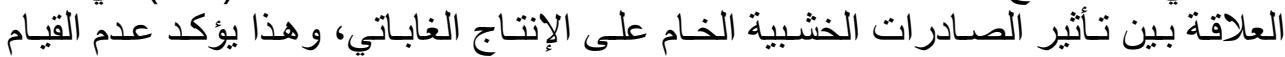

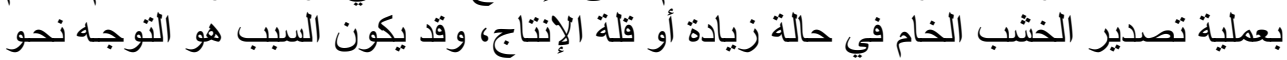

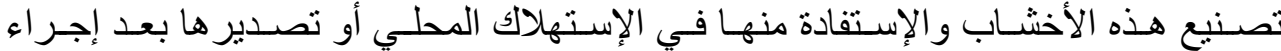

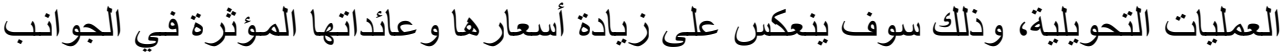

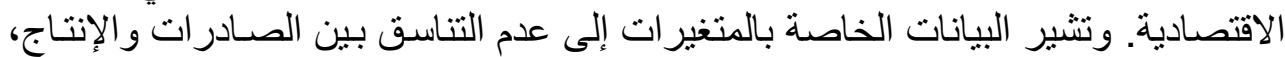

و هنالك تذبذب واسع في هذه البيانات خلال السنوات المتات المتتالية ضمن الفترة المختارة.

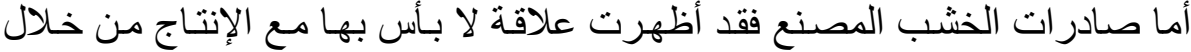

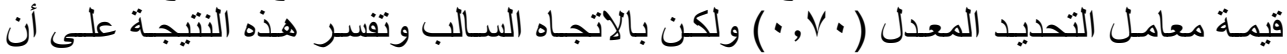

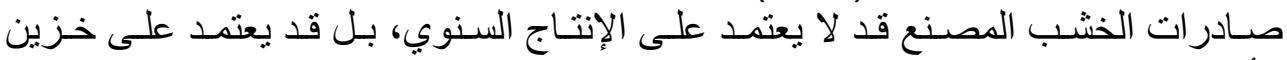
الأخشاب السابق. 
بشير وياسين[r]

r. نتائجِ العلاقة بين الصادرات الخشبية والناتج المحلي الإجمالي

أولاً اندونيسيا

يمكن ملاحظة نتائج التحليل الإحصائي لهذا الجانب من خلال الجدول الأتي:

\begin{tabular}{|c|c|c|c|}
\hline \multicolumn{4}{|c|}{ الجدول ץ } \\
\hline $\begin{array}{c}\text { No. of } \\
\text { Equation }\end{array}$ & Equation & $\mathbf{R}^{2}$ Adjusted \% & Standard Error \\
\hline 1 & $\begin{array}{l}\mathrm{Y}=1.3456 \mathrm{E} 6+0.153966^{*} \mathrm{X}_{1} \\
\mathrm{~T}(20.3876),(1.29313)\end{array}$ & 4.03 & 24.7 \\
\hline 2 & $\begin{array}{l}Y=2.04568 \mathrm{E} 6+0.0941675 * \mathrm{X}_{2} \\
\mathrm{~T}(16.2297),(-5.50612)\end{array}$ & 64.6 & 15.0 \\
\hline
\end{tabular}

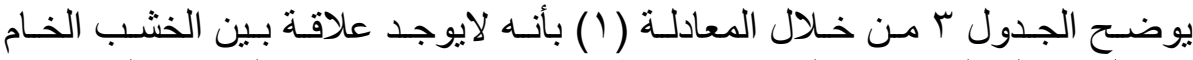

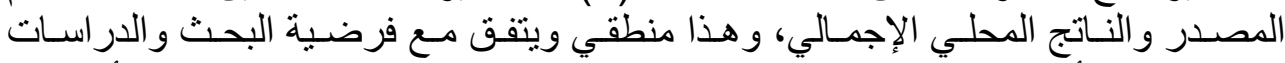

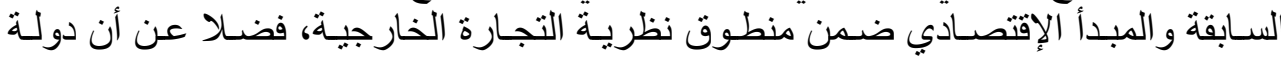

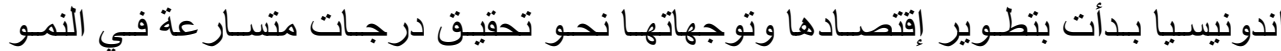

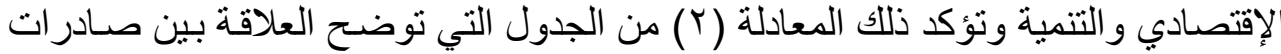

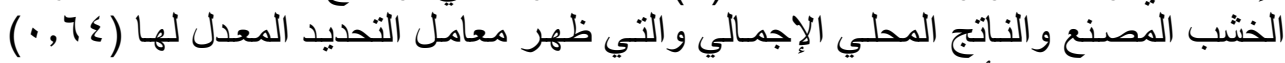

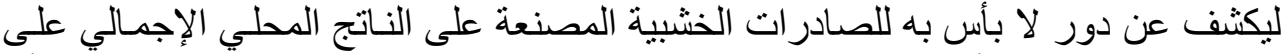

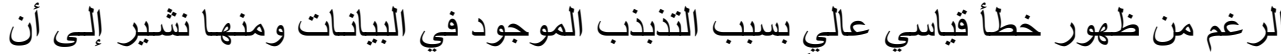

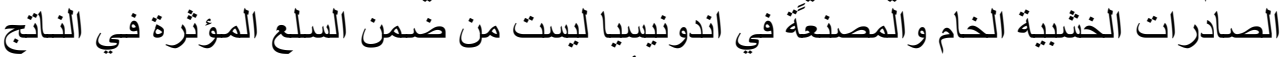

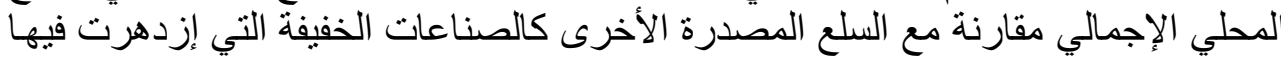
وغير ذللك.

ثنانياً - ماليزيا يمكن ملاحظة نتائج التحليل الإحصائي لهذا الجانب من خلال الجدول ؛ وكما يأتي:

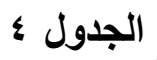

نتائج تأثير صادرات الأخشاب في الناتج المحلي الإجمالي

\begin{tabular}{|c|l|c|c|}
\hline $\begin{array}{c}\text { No. of } \\
\text { Equation }\end{array}$ & \multicolumn{1}{|c|}{ Equation } & $\mathbf{R}^{2}$ Adjusted \% & Standard Error \\
\hline 1 & $\begin{array}{l}\mathrm{Y}=450.154-0.000014718 * \mathrm{X}_{1} \\
\mathrm{~T}(17.0228),(-5.48356)\end{array}$ & 64.4 & 52.3 \\
\hline 2 & $\begin{array}{l}\mathrm{Y}=230.083+0.0000254622 * \mathrm{X}_{2} \\
\mathrm{~T}(5.10627),(2.27178)\end{array}$ & 20.6 & 78.2 \\
\hline
\end{tabular}

من خلال النظر إلى الجدول ع نجد بأن المعادلة ( (1) لتأثير الصـادرات الخشبية الخام

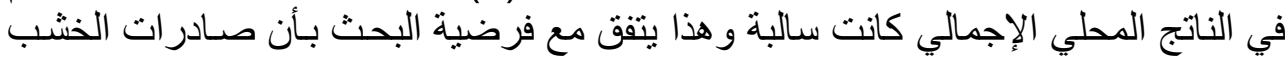

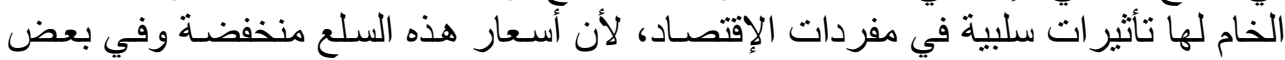
الاحيان قد تسد فقط تكاليف إنتاجها، كما أن تكاليف قطعها و إستثمار ها عالية. في حين نجد التان 


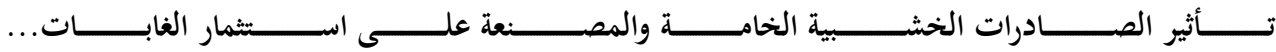

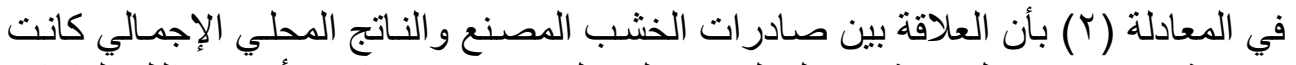

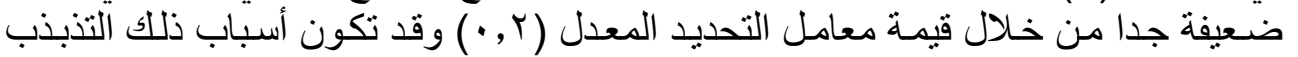

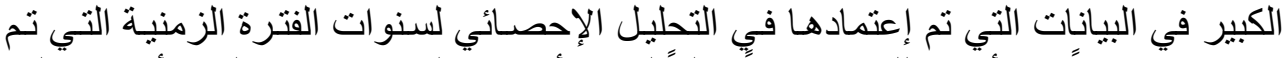

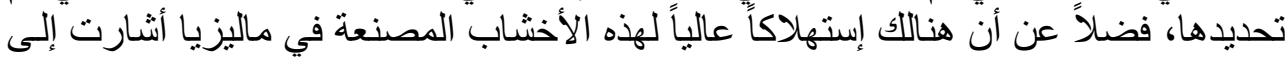

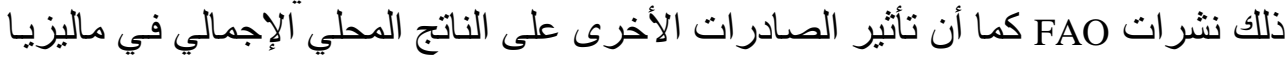

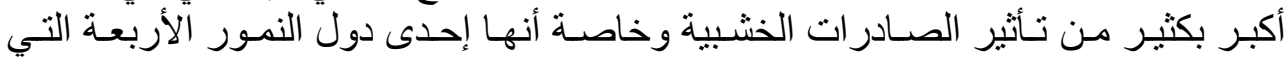

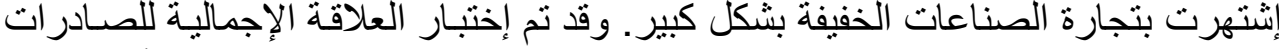

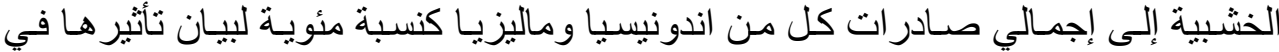

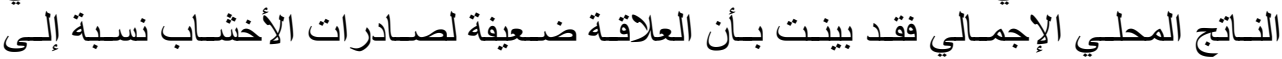
الصادرات الإجمالية التي أزدهرت في هاتين الدولتين.

\section{r. علاقة صادرات الأخشاب مع إستثمار الغابات (مساحة الغابات)} أولاًا اندونيسيا صنادات

بُوضح الجدول ه العلاقة بين صادرات الخثب الخام أو المصنع مع مساحة الغابات

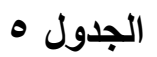

العلاقة بين صادرات الخثب الخام والمصنع مع مساحات الغابات

\begin{tabular}{|c|l|c|c|}
\hline No. of Equation & \multicolumn{1}{|c|}{ Equation } & $\mathbf{R}^{2}$ Adjusted\% & Standard Error \\
\hline 1 & $\begin{array}{l}\mathrm{Y}=104200.0-0.00680817 * \mathrm{X}_{1} \\
\mathrm{~T}(44.6933),(-1.66852)\end{array}$ & 10.6 & 23.1 \\
\hline 2 & $\begin{array}{l}\mathrm{Y}=74515.3+0.00385294 * \mathrm{X}_{2} \\
\mathrm{~T}(22.4035),(8.53759)\end{array}$ & 81.7 & 58.4 \\
\hline
\end{tabular}

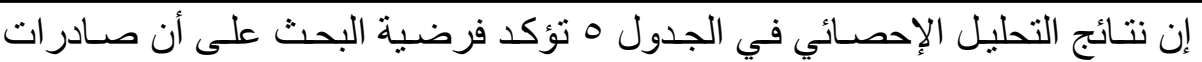

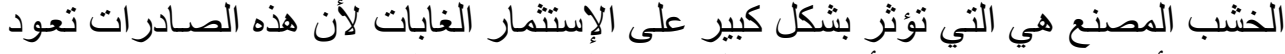

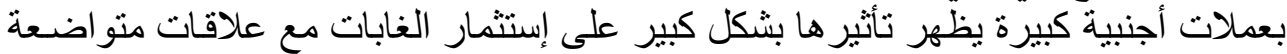

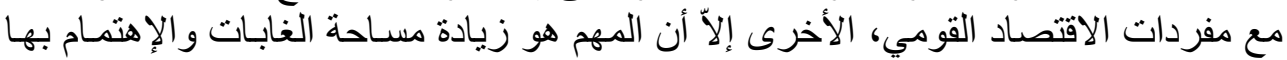

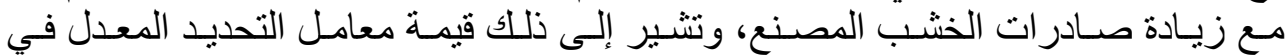

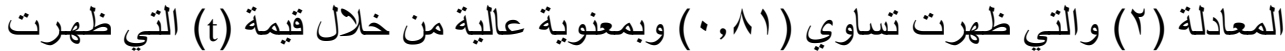

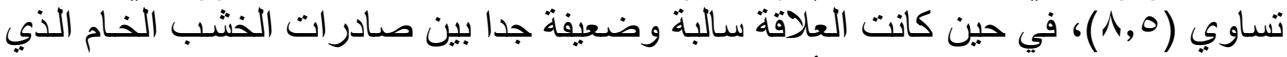

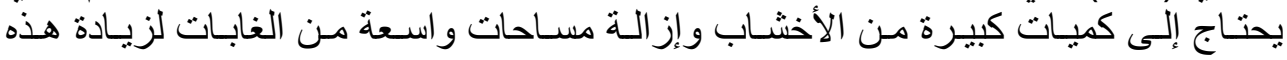
الصادر ات ولهذا ظهرت العلاقة بهذا الثكل. 
بشير وياسين[0]

ثنانياً ماليزيا

نتائج التحليل الإحصائي منلت في الجدول 7

\begin{tabular}{|c|c|c|c|}
\hline \multicolumn{4}{|c|}{ 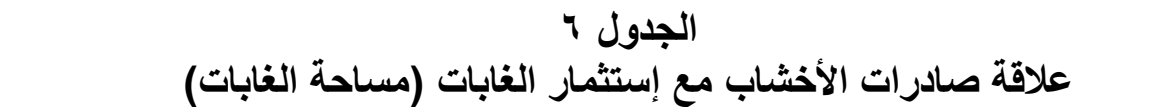 } \\
\hline $\begin{array}{l}\text { No. of } \\
\text { Equation }\end{array}$ & Equation & $\mathbf{R}^{2}$ Adjusted $\%$ & $\begin{array}{c}\text { Standard } \\
\text { Error }\end{array}$ \\
\hline 1 & $\begin{array}{l}\mathrm{Y}=20984.8+0.0000783189 * \mathrm{X}_{1} \\
\mathrm{~T}(112.029),(4.11918)\end{array}$ & 49.9 & 37.0 \\
\hline 2 & $\begin{array}{l}\mathrm{Y}=22238.6-0.000158185 * \mathrm{X}_{2} \\
\mathrm{~T}(83.9595),(-2.40093)\end{array}$ & 22.9 & 45.9 \\
\hline
\end{tabular}

من خلال الجدول أعلاه نجد بـأن العلاقة كانت ضعيفة بين صـادر ات الخشب إنب الخـام

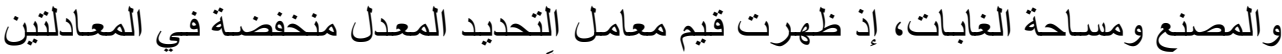

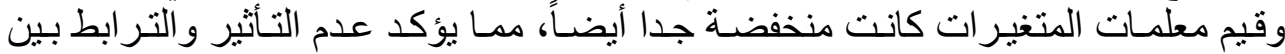

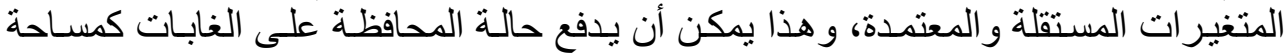

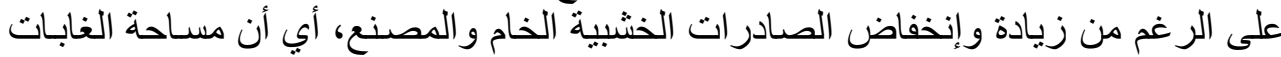

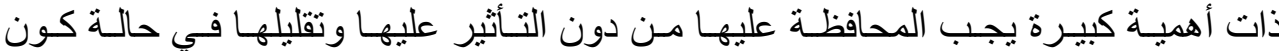

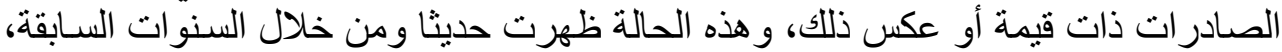

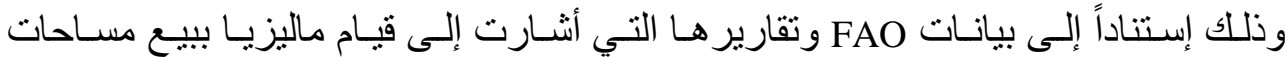

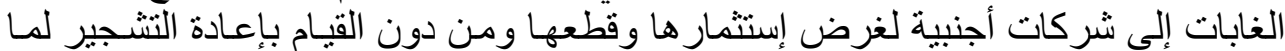

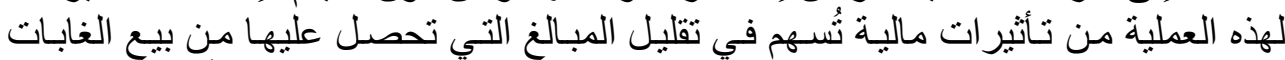

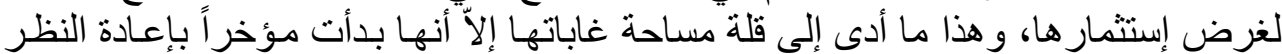

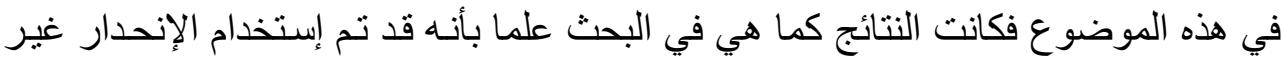

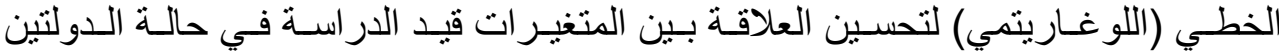

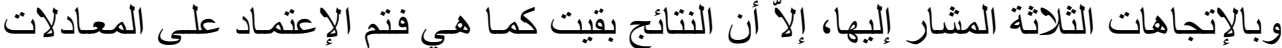

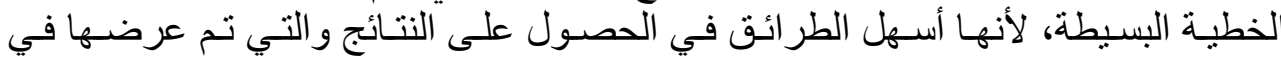

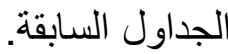

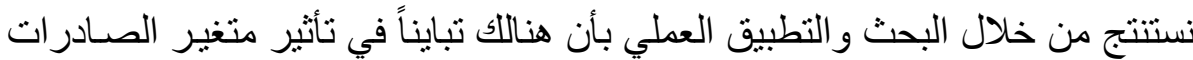

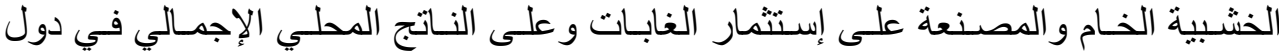

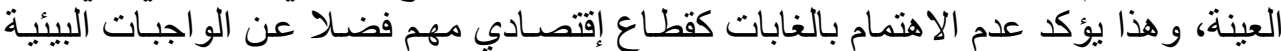

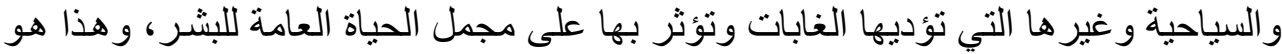

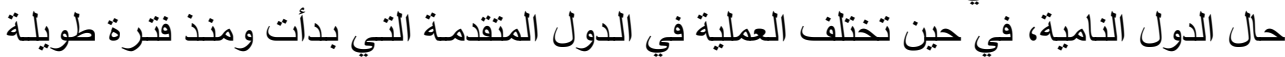

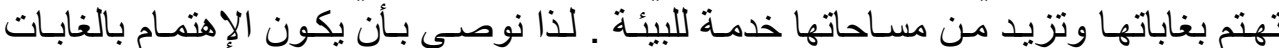

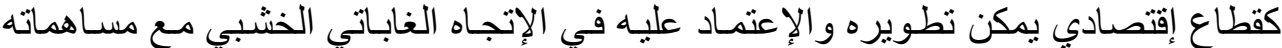

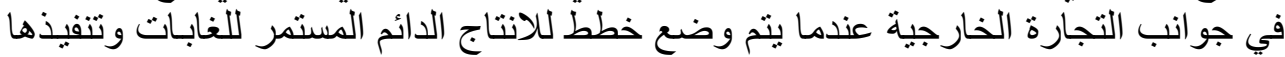
بشكل علمي للرقي بالغابات إلى مستوى القطاعات الاقتصادية المهمة في المجتمع. 


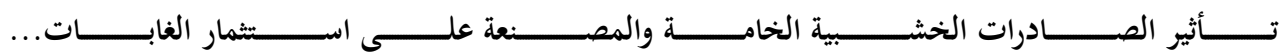

$$
\text { أولاً المراجع باللغة العربية }
$$

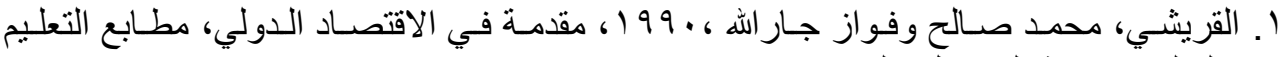

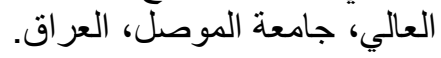

\section{ثانياً- المراجع باللغة الأجنبية}

1. Burgess, C.Joanne, 1993, Timber production, timber trade and tropical deforestation,Ambio,Vol.22,No.43 may.

2. Deborah, C. Lawrence, Leighton, Mark, and Peart, R.David, 2002, Availability and

3. Edward, Chen, 1980, Export expansion and economic growth in some Asian economics, Japan.

4. extraction of forest products in managed and primary forest around a Dayak village

5. in West Kalimantan, Indonesia.

6. Micheal, M., 1977,"Export and growth",

7. Neilson, D. and R. Fenton, 2000, "The forest industry sectors of Malaysia and Indonesia", Dana Lt.d publishing, New Zealand.

8. Schuler A., R. Taylor and P. Araman, 2001, "Competitiveness of U.S. wood furniture manufactures", Forest products J., Vol. 51,No.7/8. 